\title{
Prenatal smoking exposure and neuropsychiatric comorbidity of ADHD: a finnish nationwide population-based cohort study
}

Petteri Joelsson ${ }^{1 *}$, Roshan Chudal ${ }^{1}$, Ardesheer Talati ${ }^{2,3}$, Auli Suominen ${ }^{1}$, Alan S. Brown ${ }^{2,3,4}$ and Andre Sourander ${ }^{1,5}$

\begin{abstract}
Background: Prenatal smoking exposure has been associated with attention-deficit/hyperactivity disorder (ADHD). ADHD is commonly associated with a wide spectrum of psychiatric comorbidity. The association between smoking and neuropsychiatric comorbidity of ADHD has remained understudied. The aim of this study is to examine the association between prenatal exposure to maternal smoking and offspring ADHD, and test whether the smoking-ADHD associations are stronger when ADHD is accompanied by other lifetime neuropsychiatric comorbidities.
\end{abstract}

Methods: The study is based on a nested case-control design and includes all Finnish singletons born between 1991 and 2005 and diagnosed with ADHD by $2011(n=10,132)$, matched with four controls $(n=38,811)$ on date of birth, sex and residence in Finland.

Results: The risk for ADHD with or without comorbidity was significantly increased among offspring exposed to maternal smoking on adjusting for potential confounders ( $\mathrm{OR}=1.75, \mathrm{Cl} 95 \%=1.65-1.86)$. Compared to the only ADHD cases, subjects with comorbid conduct disorder or oppositional defiant disorder had a significantly stronger association with smoking exposure $(\mathrm{OR}=1.80, \mathrm{Cl} 95 \%=1.55-2.11)$.

Conclusions: Prenatal smoking represents an important risk factor for the ADHD comorbid with CD/ODD. Further research on the association between prenatal smoking exposure and neuropsychiatric comorbidity of ADHD is needed considering the increased risk among these subjects of an overall poor health outcome as compared to only ADHD. In particular, studies utilizing biomarkers or including subjects with neuropsychiatric conditions with and without comorbid ADHD are needed.

Keywords: ADHD, Risk factor, Smoking, Tobacco, Conduct disorder, Oppositional defiant disorder

Abbreviations: ADHD, Attention-deficit/hyperactivity disorder; ASD, Autism spectrum disorders; CD, Conduct disorder; FHDR, Finnish hospital discharge register; FMBR, Finnish medical birth register; ICD, International classification of diseases; ODD, Oppositional defiant behavior; OR, Odds ratio; PIC, Personal identity code; SES, Socioeconomic status

\footnotetext{
* Correspondence: petteri.joelsson@utu.fi

${ }^{1}$ Department of Child Psychiatry, University of Turku, Lemminkäisenkatu 3,

Lastenpsykiatrian tutkimuskeskus, 20014 Turku, Finland

Full list of author information is available at the end of the article
} 


\section{Background}

Attention-deficit/hyperactivity disorder (ADHD) is estimated to have a worldwide prevalence of $5 \%$ [1]. The disorder is characterized by impaired attention, hyperactive and impulsive symptoms with an onset at childhood $[2,3]$. ADHD is commonly associated with a wide spectrum of psychiatric comorbidity. Among ADHD cases, comorbid diagnosis of autism spectrum disorders (ASD) are found in 10-33\% $[4,5]$, conduct disorder $(C D)$ in $16-18 \%[6,7]$, learning and coordination disorders in $15-46 \%[4,6,7]$ and mental retardation in 4-8\% $[4,6]$.

Both genetic and environmental risk factors contribute to the development of ADHD [8]. Maternal smoking during pregnancy has been consistently associated with an increased risk of ADHD in the offspring $[9,10]$. Recent epidemiological studies, however, suggest that the association between maternal smoking during pregnancy and ADHD may be largely attributable to familial confounders, such as genetic traits and social factors $[11,12]$. The possibility of the teratogenic effects of smoking as a cause of ADHD should be considered, because some animal models suggest in utero nicotine exposure to be associated with neuronal cell death [13]. Smoking during pregnancy has been represented to associate with gestational hypoxia [14] and gestational hypoxia has been suggested to contribute to ADHD-like symptoms [15]. Maternal smoking during pregnancy has also been associated with increased offspring risk for several psychiatric conditions, such as pervasive developmental disorders [16], conduct disorders [17] and depression [18].

Psychiatric comorbidity complicates the assessment of ADHD [19] and might cause increasing occupational and educational disability [20]. There are few studies that have examined the association between maternal smoking during pregnancy and ADHD associated with psychiatric comorbidity, focusing mainly on conduct disorders. The results of a cross-sectional Australian study indicated that maternal smoking during pregnancy doubled the ADHD subjects' risk of being diagnosed with oppositional defiant behavior (ODD). The study was based on parental questionnaires and thus, recall bias may have contributed to the association [21]. A Norwegian study showed that smoking during pregnancy predicted increased risk for comorbid ADHD and ODD [22]. However, those findings were limited by the lack of adjustment for parental psychiatric history. Given evidence showing an increasing burden of psychiatric diseases among smokers in more recent decades [23], the potential for confounding by this covariate could be especially problematic. In this study, we examined whether maternal smoking during pregnancy is associated with varying risk among ADHD cases with different comorbid neuropsychiatric conditions, adjusting for parental psychiatric history and other potential confounders. Specifically, we tested the hypothesis that prenatal smoking exposure has a greater risk among ADHD cases with comorbid psychiatric diagnoses than cases without comorbidity. We hypothesized that comorbid $\mathrm{ADHD}$ and $\mathrm{CD} / \mathrm{ODD}$ shows the strongest association with prenatal exposure to smoking among ADHD with all co-morbid conditions. The hypotheses were based on previous study findings showing that gestational smoking exposure is associated with overall psychiatric morbidity.

\section{Methods}

This is a nationwide register study based on a nested case-control design. The sampling frame included all 900 603 liveborn children in Finland between January 1, 1991 and December 31, 2005. We utilized data from record linkages of three national registers: the Finnish Hospital Discharge Register (FHDR), Finnish Medical Birth Register (FMBR) and Finnish Central Population Register. The cases and controls were identified from the FHDR and the Finnish Central Population Register, respectively. Linkage was achieved by personal identity codes (PIC), which are assigned to all Finnish citizens and residents by the Central Population Register since 1971.

\section{National register information}

The FMBR, founded in 1987 contains standardized data on the perinatal period for all live births, and stillbirths with birth weight of at least $500 \mathrm{~g}$ or gestational age of at least 22 weeks in Finland. The FHDR includes medical diagnoses made in the Finnish public health care system. The register covers all inpatient wards, in both somatic and psychiatric hospitals, local health centres, military wards, prison hospitals, and private hospitals. Since 1998, it has also covered outpatient care in public specialized hospitals. In Finland, diagnostic classification is based on the International Classification of Diseases (ICD); ICD-8 (WHO 1967) from 1969 to 1986, ICD-9 (WHO 1977) from 1987 to 1995 and ICD-10 (WHO 1992) from 1996 onwards. This register was used in order to identify cases of ADHD and of co-morbid conditions and parental psychiatric history. The Finnish Central Population Register is a digital national archive containing basic information on Finnish citizens and permanent residents. It is maintained by the Population Register Centre and local register offices. Individual data recorded in the system includes name, personal identity code (PIC), address, citizenship, native language, family relations, date of birth, date of death, emigration/immigration, and other information. The linkage between the registers was made using the PIC, which is unchanged throughout the lifespan. 


\section{Study subjects}

The cases consisted of all Finnish singletons (citizens or permanent residents) born between January 1, 1991 and December 31, 2005 and who were diagnosed with ADHD (ICD-10: F90.X or ICD-9: 314.X) by December 31, 2011 while treated in Finnish public special health care after the age of 2 years. Among 10,409 total cases, information on maternal smoking during pregnancy was available for 10,132 , which represent the cases for this study.

For every case, we identified four controls matched by sex, date of birth (+/- 30 days) and place of birth, excluding any diagnosis of ADHD or conduct disorders resulting in 40,141 subjects. Among them, maternal smoking status during pregnancy was available on 38,811 subjects who were eventually included in this study. Study subjects with severe or profound mental retardation were excluded from both the case and control groups because it is difficult to assess the symptoms of attentional and hyperkinetic disorders among these subjects. The controls with $C D / O D D$ were not included in the dataset because the clinical features of $C D / O D D$ and $A D H D$ overlap and these disorders are difficult to differentiate from one another [24]. The case and control identifications were based on hospital diagnoses, and structured diagnostic interviews were not conducted to fully confirm whether the control group is entirely free of ADHD. In order to reduce this possibility, these controls were not included. The cases were identified from the FHDR and the controls were identified from the Finnish Central Population Register according to above-named criteria.

\section{Maternal smoking during pregnancy}

Information on maternal smoking during pregnancy was obtained from the FMBR. These were ascertained by maternity clinic nurses during routine prenatal visits during the second trimester of pregnancy and documented in health records. Maternal smoking during pregnancy was classified as: non-smokers, smoking only during the first trimester and smoking after first trimester.

\section{Covariates}

The covariates used in the analyses were: maternal and paternal psychiatric history, maternal history of any substance use, maternal and paternal age at birth of offspring, maternal and paternal immigrant status, maternal socioeconomic status (SES), birth weight for gestational age, Apgar scores at $1 \mathrm{~min}$, number of previous births and gestational age. Covariates were classified as represented in Tables 1 and 2. Data on maternal and paternal age and immigrant status were obtained from the Finnish Central Population Register. Maternal SES, maternal marital status, birth weight for gestational age,
Apgar scores at $1 \mathrm{~min}$ and gestational age were obtained from the FMBR.

A father was defined as having a "psychiatric history" if he had been diagnosed with any mental health disorder based on the classification of ICD-8 from year 1969 to 1986 (291-308), ICD-9 from year 1987 to 1995 (291-316) or ICD-10 from year 1996 onwards (F10-99, excluding mental retardation F70-79). Maternal psychopathology was defined correspondingly with the exception of separating "history of substance use history" and "any other psychiatric history" as independent covariates. These were separated because maternal diagnosis of substance use might be an indicator of teratogenic risk factors and thus it differs from paternal substance use diagnosis and other maternal diagnoses. A mother was defined as having a "history of substance use disorder" if she had been diagnosed accordingly based on the classification of ICD-8 from year 1969 to 1986 (291, 303, 304), ICD-9 from year 1987 to $1995(291,292,303,304,305)$ or ICD-10 from year 1996 onwards (F10-19). Data on parental psychiatric diagnoses were obtained from the FHDR.

\section{Psychiatric Comorbidity}

The lifetime comorbid psychiatric diagnoses of the subjects were obtained from the FHDR according to ICD-10 (F10-F99) similar to that used in the case identification 2011. Only those psychiatric conditions with onset typically during early childhood and with high rates of comorbidity with ADHD were included in the study. These conditions were mental retardation (F70-F79), pervasive developmental disorders, including autism spectrum disorders (ASD) (F84); Tourette syndrome (F95.2); conduct disorders, including oppositional defiant disorder (CD/ODD) (F90.1, F91, F92) and learning and coordination disorders (F80-F83). The corresponding comorbid psychiatric conditions were classified into five groups.

Seventy-six percent of the ADHD cases had at least one comorbid diagnosis. Learning and coordination disorder was the most common comorbid diagnostic group (48.1\%). The other most common comorbid diagnoses were: $C D / O D D(28.1 \%)$, anxiety disorders (13.6\%), autism spectrum disorders (11.9\%), depression (8.9\%,) and mental retardation $(3.7 \%)$. The psychiatric comorbid patterns of the sample have been reported recently in more detail [25]. These findings were in general consistent with previous studies [5]. The overlap between the observed comorbidities is shown in Additional file 1: Table S1.

Because these comorbidities showed significant overlap each case was assigned to only one comorbid group in a hierarchical manner in the following order: first mental retardation; second ASD; third Tourette syndrome; fourth $C D / O D D$ and fifth learning and coordination disorders. 
Table 1 Potential confounding factors in relation to maternal smoking during pregnancy in controls

\begin{tabular}{|c|c|c|c|c|c|c|}
\hline & & No smoking & $\begin{array}{l}\text { Smoking only } \\
\text { in first trimester }\end{array}$ & $\begin{array}{l}\text { Smoking after } \\
\text { first trimester }\end{array}$ & $p$ & $x^{2}$ \\
\hline \multirow[t]{4}{*}{ Maternal age at birth } & $\leq 19$ years & $529(1.7 \%)$ & 48 (7.9\%) & $322(6.4 \%)$ & \multirow[t]{4}{*}{$p<0.001$} & \multirow[t]{4}{*}{647.55} \\
\hline & 20-29 years & 15,660 (50.1\%) & $365(59.8 \%)$ & 2836 (56.2 \%) & & \\
\hline & 30-39 years & $14,195(45.4 \%)$ & 186 (30.5 \%) & 1762 (34.9\%) & & \\
\hline & $\geq 40$ years & $886(2.8 \%)$ & $11(1.8 \%)$ & $123(2.4 \%)$ & & \\
\hline \multirow[t]{4}{*}{ Paternal age at birth ${ }^{a}$} & $\leq 19$ years & $106(0.3 \%)$ & $11(1.9 \%)$ & 95 (1.9\%) & \multirow[t]{4}{*}{$p<0.001$} & \multirow[t]{4}{*}{413.72} \\
\hline & $20-29$ years & $11,414(36.8 \%)$ & $297(49.9 \%)$ & 2255 (45.9 \%) & & \\
\hline & 30-39 years & 16,485 (53.1\%) & 247 (41.5 \%) & 2160 (44.0\%) & & \\
\hline & $\geq 40$ years & 3052 (9.8 \%) & 40 (6.7 \%) & 404 (8.2 \%) & & \\
\hline \multirow{2}{*}{$\begin{array}{l}\text { History of maternal } \\
\text { psychopathology }\end{array}$} & Yes & 3321 (10.6 \%) & $92(15.1 \%)$ & $927(18.4 \%)$ & \multirow[t]{2}{*}{$p<0.001$} & \multirow[t]{2}{*}{258.83} \\
\hline & No & $27,949(89.4 \%)$ & 518 (84.9\%) & 4116 (81.6 \%) & & \\
\hline \multirow{2}{*}{$\begin{array}{l}\text { History of maternal } \\
\text { substance abuse }\end{array}$} & Yes & $357(1.1 \%)$ & 22 (3.6 \%) & 368 (7.3 \%) & \multirow[t]{2}{*}{$p<0.001$} & \multirow[t]{2}{*}{837.97} \\
\hline & No & 30,913 (98.9 \%) & $588(96.4 \%)$ & 4675 (92.7 \%) & & \\
\hline \multirow{2}{*}{$\begin{array}{l}\text { History of paternal } \\
\text { psychopathology }\end{array}$} & Yes & 3387 (10.9 \%) & $109(18.3 \%)$ & 1101 (22.4\%) & \multirow[t]{2}{*}{$p<0.001$} & \multirow[t]{2}{*}{528.64} \\
\hline & No & 27,670 (89.1\%) & 486 (81.7 \%) & 3813 (77.6 \%) & & \\
\hline \multirow[t]{2}{*}{ Previous births } & 0 & $12,557(40.2 \%)$ & $381(62.5 \%)$ & 2139 (42.4 \%) & \multirow[t]{2}{*}{$p<0.001$} & \multirow[t]{2}{*}{129.23} \\
\hline & $\geq 1$ & 18,713 (59.8\%) & $229(37.5 \%)$ & 2904 (57.6 \%) & & \\
\hline \multirow{3}{*}{$\begin{array}{l}\text { Weight for gestational } \\
\text { age }^{\mathrm{b}}\end{array}$} & $<-2 S D$ & $716(2.3 \%)$ & 16 (2.6 \%) & 285 (5.7 \%) & \multirow[t]{3}{*}{$p<0.001$} & \multirow[t]{3}{*}{219.66} \\
\hline & -2 to $+2 S D$ & 29,330 (94.1\%) & $571(93.9 \%)$ & 4641 (92.4 \%) & & \\
\hline & $\geq+2 S D$ & $1141(3.7 \%)$ & 21 (3.5 \%) & 95 (1.9\%) & & \\
\hline \multirow[t]{5}{*}{ Maternal SES } & Upper white collar & 5325 (17.0 \%) & 40 (6.6 \%) & $263(5.2 \%)$ & \multirow[t]{5}{*}{$p<0.001$} & \multirow[t]{5}{*}{1179.59} \\
\hline & Lower white collar & $14,404(46.1 \%)$ & $234(38.4 \%)$ & 1890 (37.5 \%) & & \\
\hline & Blue collar & 4809 (15.4 \%) & $161(26.4 \%)$ & 1552 (30.8 \%) & & \\
\hline & Others & 4663 (14.9 \%) & $129(21.2 \%)$ & $901(17.9 \%)$ & & \\
\hline & Missing & 2069 (6.6 \%) & $46(7.5 \%)$ & 437 (8.7 \%) & & \\
\hline \multirow{2}{*}{$\begin{array}{l}\text { Maternal immigrant } \\
\text { status }\end{array}$} & Not born in Finland & $491(1.6 \%)$ & $13(2.1 \%)$ & 38 (0.8 \%) & \multirow[t]{2}{*}{$p<0.001$} & \multirow[t]{2}{*}{21.91} \\
\hline & Born in Finland & $30,779(98.4 \%)$ & 597 (97.9\%) & 5005 (99.2 \% & & \\
\hline \multirow{2}{*}{$\begin{array}{l}\text { Paternal immigrant } \\
\text { status }^{a}\end{array}$} & Not born in Finland & $557(1.8 \%)$ & $9(1.5 \%)$ & 85 (1.7 \%) & $p<0.841$ & 0.35 \\
\hline & Born in Finland & $30,500(98.2 \%)$ & 586 (98.5 \%) & 4829 (98.3 \%) & & \\
\hline Apgar score at $1 \min ^{c}$ & $<6$ & 1151 (3.7\%) & $30(4.9 \%)$ & 195 (3.9\%) & $p<0.229$ & 2.95 \\
\hline & $7-10$ & 30,086 (96.3 \%) & $577(95.1 \%)$ & 4841 (96.1 \%) & & \\
\hline$G_{\text {Gestational age }}^{d}$ & $\leq 32$ weeks & $195(0.6 \%)$ & $3(0.5 \%)$ & $47(1.0 \%)$ & $p<0.029$ & 14.11 \\
\hline & 33-36 weeks & $1171(3.8 \%)$ & 19 (3.1\%) & $218(4.3 \%)$ & & \\
\hline & 37-41 weeks & $28,407(91.0 \%)$ & $553(90.8 \%)$ & $4546(90.5 \%)$ & & \\
\hline & $\geq 42$ weeks & 1431 (4.6\%) & 34 (5.6\%) & $212(4.2 \%)$ & & \\
\hline
\end{tabular}

adata missing: 357 subjects

bdata missing: 145 subjects

'data missing 43 subjects

${ }^{d}$ data missing 87 subjects

For example, if a case was diagnosed with both mild mental retardation and Tourette syndrome, she/he would be assigned to the group of mental retardation. If the case had none of the previous conditions, he/she would be classified into group six, "ADHD without comorbidities". As listed in Table 4, the hierarchy was based on the chronicity, severity and impairment of functional abilities in each disorder. For example, mental retardation and autism are consistently severe and lifelong conditions which impair daily activities.

\section{Statistical analyses}

Multivariable analyses were conducted initially to test the significance of association between covariates and 
Table 2 Potential confounding factors in relation to case-control status

\begin{tabular}{|c|c|c|c|c|c|}
\hline & & Cases & Controls & $p$ & $x^{2}$ \\
\hline \multirow[t]{4}{*}{ Maternal age at birth } & $\leq 19$ years & $672(6.7 \%)$ & 899 (2.4 \%) & \multirow[t]{4}{*}{$p<0.001$} & \multirow[t]{4}{*}{603.69} \\
\hline & 20-29 years & 5711 (56.5 \%) & $18,861(51.1 \%)$ & & \\
\hline & 30-39 years & 3475 (34.4 \%) & 16,143 (43.7 \%) & & \\
\hline & $\geq 40$ years & $254(2.5 \%)$ & $1020(2.8 \%)$ & & \\
\hline \multirow[t]{4}{*}{ Paternal age at birth ${ }^{a}$} & $\leq 19$ years & $211(2.2 \%)$ & $212(0.6 \%)$ & \multirow[t]{4}{*}{$p<0.001$} & \multirow[t]{4}{*}{330.41} \\
\hline & 20-29 years & 4322 (44.2 \%) & 13,966 (38.2 \%) & & \\
\hline & 30-39 years & $4358(44.5 \%)$ & $18,892(51.7 \%)$ & & \\
\hline & $\geq 40$ years & 896 (9.2 \%) & 3496 (9.6 \%) & & \\
\hline \multirow{2}{*}{$\begin{array}{l}\text { History of maternal } \\
\text { psychopathology }\end{array}$} & Yes & $2610(25.8 \%)$ & 4340 (11.8 \%) & \multirow[t]{2}{*}{$p<0.001$} & \multirow[t]{2}{*}{1154.75} \\
\hline & No & 7502 (74.2 \%) & 32,583 (88.3 \%) & & \\
\hline \multirow{2}{*}{$\begin{array}{l}\text { History of maternal } \\
\text { substance abuse }\end{array}$} & Yes & $685(6.8 \%)$ & 747 (2.0 \%) & \multirow[t]{2}{*}{$p<0.001$} & \multirow[t]{2}{*}{525.72} \\
\hline & No & 9427 (93.2 \%) & 36,176 (98.0 \%) & & \\
\hline \multirow{2}{*}{$\begin{array}{l}\text { History of paternal } \\
\text { psychopathology }\end{array}$} & Yes & 2382 (24.3 \%) & 4597 (12.6 \%) & \multirow[t]{2}{*}{$p<0.001$} & \multirow[t]{2}{*}{779.19} \\
\hline & No & 7405 (75.7 \%) & $31,969(87.4 \%)$ & & \\
\hline \multirow[t]{2}{*}{ Previous births } & 0 & 4683 (46.3 \%) & $15,077(40.8 \%)$ & \multirow[t]{2}{*}{$p<0.001$} & \multirow[t]{2}{*}{98.03} \\
\hline & $\geq 1$ & 5429 (53.7 \%) & 21,846 (59.2 \%) & & \\
\hline \multirow{3}{*}{$\begin{array}{l}\text { Weight for gestational } \\
\text { age }^{\mathrm{b}}\end{array}$} & $<-2 \mathrm{SD}$ & $569(5.6 \%)$ & $1017(2.8 \%)$ & \multirow[t]{3}{*}{$p<0.001$} & \multirow[t]{3}{*}{189.09} \\
\hline & -2 to +2 SD & 9167 (91.0 \%) & 34,542 (93.8 \%) & & \\
\hline & $\geq+2 S D$ & $338(3.4 \%)$ & $1257(3.4 \%)$ & & \\
\hline \multirow[t]{5}{*}{ Maternal SES } & Upper white collar & 861 (8.5 \%) & 5628 (17.7 \%) & \multirow[t]{5}{*}{$p<0.001$} & \multirow[t]{5}{*}{593.56} \\
\hline & Lower white collar & 3986 (39.4 \%) & 6522 (15.2 \%) & & \\
\hline & Blue collar & 2439 (24.1\%) & 16,528 (44.8 \%) & & \\
\hline & Others & 1959 (19.4 \%) & 5693 (15.4 \%) & & \\
\hline & Missing & 867 (8.6 \%) & 2552 (6.9 \%) & & \\
\hline \multirow{2}{*}{$\begin{array}{l}\text { Maternal immigrant } \\
\text { status }\end{array}$} & Not born in Finland & $223(2.2 \%)$ & $542(1.5 \%)$ & \multirow[t]{2}{*}{$p<0.001$} & \multirow[t]{2}{*}{26.04} \\
\hline & Born in Finland & 9889 (97.8 \%) & 36,381 (98.5 \%) & & \\
\hline \multirow{2}{*}{$\begin{array}{l}\text { Paternal immigrant } \\
\text { status }^{a}\end{array}$} & Not born in Finland & $368(3.8 \%)$ & $651(1.8 \%)$ & \multirow[t]{2}{*}{$p<0.001$} & 136.41 \\
\hline & Born in Finland & 9419 (96.2 \%) & 35,915 (98.2 \%) & & \\
\hline Apgar score at $1 \min ^{c}$ & $<6$ & 537 (5.3 \%) & $1376(3.7 \%)$ & $p<0.001$ & 48.65 \\
\hline & $7-10$ & 9565 (94.7 \%) & 35,504 (96.3 \%) & & \\
\hline Gestational age & $\leq 32$ weeks & $224(2.2 \%)$ & $245(0.7 \%)$ & $p<0.001$ & 219.24 \\
\hline & 33-36 weeks & $564(5.6 \%)$ & $1408(3.8 \%)$ & & \\
\hline & 37-41 weeks & 8833 (87.6\%) & 33,506 (91.0\%) & & \\
\hline & $\geq 42$ weeks & $460(4.6 \%)$ & $1677(4.5 \%)$ & & \\
\hline
\end{tabular}

\footnotetext{
adata missing 682 subjects

bdata missing: 107 subjects
}

'data missing 53 subjects

maternal smoking among controls as well as between covariates and ADHD diagnosis using Pearson's $\chi^{2}$-test. The primary outcome variable was an ADHD diagnosis (no/yes). Conditional logistic regression models were used to examine the association between maternal smoking and ADHD with odds ratios (OR) and $95 \%$ confidence intervals (CI).

The unadjusted model was used to evaluate the association between maternal smoking and the outcome in the entire sample. Maternal smoking was classified first as a dichotomous variable and then as a categorical variable by timing during gestation (no smoking /during first trimester only/after first trimester). The multivariable logistic regression model was used to evaluate the associations adjusting for covariates. In this comparison the reference group were the controls. Statistical significance (2-tailed) was judged at $p<0.05$. 
Subsequently, we compared the relationships between maternal smoking and odds for ADHD alone and with each comorbid condition. Finally, we compared the relationships between maternal smoking and each ADHD-comorbid group with the "ADHD without comorbidities". In the multivariable regression model adjustment was made for covariates with associations between both smoking and the outcome covariates at $p<0.1$. The interaction term between ADHD with each comorbidity versus "ADHD without comorbidity" was assessed to compare the magnitude of ORs for smoking during pregnancy. In addition, differences in the magnitude of the ORs for ADHD between smoking only during the first trimester and smoking after the first trimester were tested correspondingly.

Statistical analyses were performed with SAS statistical software [26].

\section{Results}

Among the potential covariates, maternal and paternal psychiatric history, maternal substance abuse history, maternal and paternal age at birth, maternal socioeconomic status, weight for gestational age, number of previous births and gestational age were associated with both maternal smoking during pregnancy among the controls and ADHD and were included as covariates in the analyses (Tables 1 and 2). Weight for gestational age and gestational age were not included simultaneously as covariates in analyses because of their potential multicollinearity.

As shown in Table 3, $30.3 \%$ of the mothers of cases smoked during pregnancy, whereas the corresponding figure was $15.3 \%$ for the mothers of controls. The odds for $\mathrm{ADHD}$ in the entire sample was significantly increased among subjects exposed to maternal smoking during pregnancy when adjusted for confounders (OR 1.73, $95 \%$ CI: $1.62-1.84, p<0.001)$. Among the cases, $2.2 \%$ of mothers smoked only during the first trimester and $28.1 \%$ after the first trimester. Among controls, the corresponding figures were $1.6 \%$ and $13.7 \%$. There were increased odds for ADHD associated with maternal smoking after first trimester (adjusted OR 1.79, 95 \% CI: $1.68-1.92, p<0.001)$ as well as smoking only during the first trimester (OR 1.24, 95 \% CI: 1.03-1.50, $p<0.012$ ). There were significant differences in the magnitude of the odds for ADHD between smoking only during the first trimester and smoking after first trimester $(p<0.001)$. The difference in odds for ADHD between smoking during pregnancy and during the first trimester only was statistically significant $(p<0.001)$.

The associations between maternal smoking during pregnancy and odds of ADHD with each comorbid condition are shown in the Table 4. Smoking during pregnancy was examined as a binary variable (yes/no) instead of considering specific periods because the number of subjects exposed to smoking only during the first trimester was not sufficient for statistical analysis in each diagnostic group. Smoking during pregnancy was a risk factor for ADHD with each comorbid disorder. The highest risk was seen with comorbid CD/ODD (OR $=2.54$ $95 \%$ CI 2.24-2.88, $p<0.001)$ and the lowest with learning disorders (OR $=1.5195 \%$ CI 1.35-1.68, $p<0.001)$. In addition with other confounders the results were adjusted first with weight for gestational age (ADHD without comorbidities OR 1.59, $95 \%$ CI 1.43-1.77), second with gestational age (OR $1.6195 \%$ CI 1.45-1.78) and third with neither (OR 1.61, $95 \%$ CI 1.45-1.79). The results were similar in all three models for all comorbid categories.

As shown in Table 5, comparing each ADHDcomorbid group with the "ADHD without comorbidities" the comorbid CD/ODD was the only diagnostic group which had a significantly stronger association with smoking (adjusted OR $1.8095 \%$ CI 1.55-2.11, $p<0.001)$. The association between smoking and comorbid CD/ODD was significantly stronger compared to the respective associations for each of the other ADHD-comorbid diagnostic groups in unadjusted models. In the adjusted model only the groups of ADHD subjects with comorbid Tourette syndrome and mental retardation did not differ significantly from the group with ADHD and CD/ODD.

\section{Discussion}

The present study has several findings which add to the evidence of a complex association between exposure to

Table 3 Associations between ADHD and maternal smoking during pregnancy

\begin{tabular}{|c|c|c|c|c|}
\hline \multirow[b]{2}{*}{ Maternal smoking status } & \multicolumn{2}{|l|}{ Frequencies } & \multicolumn{2}{|l|}{ OR $(95 \% \mathrm{Cl})$} \\
\hline & Cases $n(\%)$ & Controls n (\%) & Unadjusted & Adjusted $^{a}$ \\
\hline Not smoking during pregnancy & 7068 (69.7 \%) & $33,158(84.7 \%)$ & Reference & Reference \\
\hline Smoking during pregnancy (Yes/No) & 3064 (30.3\%) & $5653(15.3 \%)$ & $2.44(2.32-2.58)$ & $1.75(1.65-1.86)$ \\
\hline Smoking after first trimester & 2839 (28.1\%) & $5043(13.7 \%)$ & $2.54(2.41-2.68)$ & $1.81(1.71-1.93)$ \\
\hline Smoking only during first trimester & $225(2.2 \%)$ & $610(1.7 \%)$ & $1.66(1.41-1.94)$ & $1.25(1.05-1.48)$ \\
\hline
\end{tabular}

$O R$ odds ratio, $\mathrm{Cl}$ confidence interval

${ }^{a}$ Adjusted for maternal and paternal psychiatric history, maternal substance use history, maternal and paternal age at birth, maternal socioeconomic status, birth weight for gestational age, number of previous births and maternal marital status 
Table 4 Associations between ADHD and maternal smoking during pregnancy among comorbid neuropsychiatric conditions

\begin{tabular}{lllll}
\hline & $\begin{array}{l}\text { Cases exposed to smoking } \\
\text { during pregnancy } n(\%)\end{array}$ & $\begin{array}{l}\text { Controls exposed to smoking } \\
\text { during pregnancy } n(\%)\end{array}$ & $\begin{array}{l}\text { OR (95 \% Cl) } \\
\text { Unadjusted }\end{array}$ & $\begin{array}{l}\text { OR (95 \% Cl) } \\
\text { Adjusted }\end{array}$ \\
\hline ADHD + Mental Retardation $(N=374)$ & $106(28.3 \%)$ & $173(12.6 \%)$ & $2.79(2.10-3.72)$ & $1.93(1.38-2.69)$ \\
ADHD + ASD $(n=1134)$ & $299(26.4 \%)$ & $593(14.3 \%)$ & $2.14(1.82-2.51)$ & $1.59(1.33-1.91)$ \\
ADHD + Tourette $(n=172)$ & $45(26.2 \%)$ & $89(14.3 \%)$ & $2.06(1.36-3.13)$ & $1.74(1.06-2.86)$ \\
ADHD + CD/ODD $(n=2339)$ & $950(40.6 \%)$ & $1308(15.4 \%)$ & $3.96(3.55-4.41)$ & $2.54(2.24-2.88)^{\mathrm{b}}$ \\
ADHD + Learning and coordination & $799(27.0 \%)$ & $1726(16.0 \%)$ & $1.98(1.80-2.19)$ & $1.51(1.35-1.68)$ \\
disorders $(n=2957)$ & & $1764(15.4 \%)$ & $2.11(1.92-2.32)$ & $1.59(1.43-1.77)$ \\
ADHD without comorbidities $(n=3136)$ & $865(27.6 \%)$ & &
\end{tabular}

Reference category in each group were their designated controls $O R$ odds ratio, $C l$ confidence interval

${ }^{a}$ Adjusted for:maternal and paternal psychiatric history, maternal substance abuse history, maternal and paternal age at birth, maternal socioeconomic status, birth weight for gestational age, number of previous births and maternal marital status

bOR was significantly different from "ADHD without comorbidities", $p<0.001$

smoking during pregnancy and later ADHD with comorbid conditions. First, prenatal smoking exposure was associated with increased risk of ADHD with comorbid neuropsychiatric disorders. Second, comparing each of the co-morbid groups with the control group, the strongest association was found with ADHD comorbid with $\mathrm{CD} / \mathrm{ODD}$. Third, the group with ADHD and CD/ODD was the only group showing a statistically significant association with smoking compared to the group of ADHD without comorbidities. To our knowledge, this is the first study to report these associations in a large nationwide sample.

The association between maternal smoking during pregnancy and, offspring ADHD and, specifically $\mathrm{CD} /$ ODD status has several possible explanations. First, exposure to smoking during pregnancy might have direct intrauterine effects mediated by nicotine contributing to risk for ADHD and CD/ODD. Nicotine has been shown to transfer across the placenta to the fetus [27]. Also, nicotine is an agonist of acetylcholine and can in this way interfere with fetal central nervous system

Table 5 The comparisons of associations between maternal smoking and groups with ADHD and comorbid conditions and with ADHD without co-morbid conditions

\begin{tabular}{lll}
\hline & $\begin{array}{l}\text { Unadjusted OR } \\
(95 \% \mathrm{Cl})\end{array}$ & $\begin{array}{l}\text { Adjusted OR } \\
(95 \% \mathrm{Cl})\end{array}$ \\
\hline $\begin{array}{l}\text { ADHD + Mental Retardation } \\
(n=374)\end{array}$ & $1.32(0.98-1.79)$ & $1.32(0.96-1.83)$ \\
ADHD + ASD $(n=1134)$ & $1.01(0.84-1.22)$ & $0.98(0.80-1.20)$ \\
ADHD + Tourette $(n=172)$ & $0.98(0.64-1.50)$ & $1.06(0.67-1.68)$ \\
ADHD + CD/ODD $(n=2339)$ & $1.87(1.62-2.16)$ & $1.80(1.55-2.11)$ \\
$\begin{array}{l}\text { ADHD + Learning and } \\
\text { Coordination disorders }(n=2957)\end{array}$ & $0.94(0.82-1.07)$ & $0.96(0.83-1.11)$ \\
$\begin{array}{l}\text { ADHD without comorbidities } \\
(n=3136)\end{array}$ & Reference & Reference
\end{tabular}

$(n=3136)$

OR odds ratio, $\mathrm{Cl}$ confidence interval

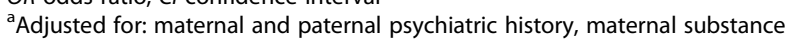
abuse history, maternal and paternal age at birth, maternal socioeconomic status, birth weight for gestational age and number of previous births maturation. [28]. In animal models nicotine exposure is associated with increased locomotor activity which is considered as an indicator for ADHD [29]. Furthermore, nicotine exposure during pregnancy has been argued to increase risk for later conduct problems [30]. Second, the association of smoking and CD/ODD and ADHD might partially be explained by gene-environmentinteraction. Early smoking exposure might increase the risk of comorbid ADHD and CD/ODD particularly among children with a specific genetic vulnerability. For example, children exposed to maternal smoking during pregnancy were given higher hyperactive-impulsive and oppositional scores if they were homozygous for the 10repeat dopamine transporter gene allele [31]. Third, smoking might be a proxy for risk factors leading to ADHD and CD/ODD with independent mechanisms. The overall tendency to smoke cigarettes correlates with the level of ADHD symptoms [32]. It is possible that among smoking mothers, a significant proportion have sub-clinical ADHD which are not diagnosed in healthcare services and are thus unidentified. Therefore, smoking exposure might be an indicator of genetic risk factors. Simultaneously, smoking is also associated with harsh parenting practices [33] which are associated with disruptive behavior of the offspring [34]. Furthermore, poor parenting skills have been suggested to increase the risk of comorbid psychiatric conditions among children with ADHD who might be especially vulnerable to harsh or non-supportive parenting styles [35].

The association between prenatal smoking exposure and offspring ADHD in general was in line with previous similar studies reporting findings of ORs ranging between 1.5 and $2.4[9,10]$. The differences of the odds between smoking only during the first trimester and after the first trimester suggest a possibility of a doseresponse effect. This hypothesis is supported by a previous finding of a linear correlation between number of cigarettes smoked during pregnancy and severity of attentional problems [36]. The dose-response-effect could 
be mediated by chronic hypoxia to the fetal brain as animal models have demonstrated association between neonatal hypoxia and ADHD-like behavior [15]. The fetal brain could also be more vulnerable to smoking exposure in the later periods of pregnancy. Alternatively, the ability to quit smoking after the first trimester might be a proxy for unknown protective maternal attributes. As shown in the Table 1 , the mothers who smoked after the first trimester had more often a history of psychiatric disorders compared to mothers who ceased smoking. It is unclear whether, for example, bipolar disorder or schizophrenia are more common within mothers smoking after the first trimester, especially given that these parental disorders have been associated with offspring ADHD [37].

The present study is based on a large nationwide sample, and the analyses were adjusted with several confounders. However, there are limitations that need to be considered while interpreting the findings. First, the subjects include only the ADHD cases referred to specialized mental health services and assumingly these represent mainly the patients with the most severe symptoms of ADHD. The healthcare services in Finland are universal and publicly funded; children are exempted from the generally low patient fees. Because of this the number of severe ADHD cases missing due to lack of access to health services is expected to be small. Second, the maternal smoking status was based on a self-report. Previous studies have shown that pregnant mothers under-report their smoking. Actually, between 7 and $22 \%$ of the self-reported non-smokers were smokers according to the blood and urine cotinine levels [38, 39]. Third, there are several potential confounders not available in this study, e.g. paternal smoking, and prenatal alcohol and drug exposure. However, information about maternal substance use diagnosis was included in the analyses. Fourth, we did not have information on children diagnosed only with CD/ODD. Therefore, we are not able to address the question whether the association between smoking and ADHD and CD/ODD could be due to the effects of smoking on CD/ODD independent of ADHD. Indeed, there is evidence of the association between smoking exposure and conduct problems [17]. However, few previous studies have not shown maternal smoking to have an effect on conduct problems when the results have been adjusted with parental psychiatric history and socioeconomic factors [40, 41]. Fifth, controls with CD/ODD were excluded which could strengthen the association between smoking and ADHD comorbid with CD/ODD compared to other diagnostic groups. However, the cumulative incidence of CD/ODD diagnosis in Finland by the age of 14 has recently been reported to be only $1.4 \%$ [42] and, thus, the exclusion is expected to have a modest influence to the results at the most. Furthermore, the association between smoking and ADHD with comorbid CD/ODD was significantly stronger compared to the group without comorbidities. This indicates that our findings cannot be explained only by the exclusion of controls with a CD/ODD diagnosis. Sixth, common internalizing disorders, such as anxiety and depression, were not included in the analysis. Anxiety and depression may have onset at adolescence or adulthood whereas the included disorders typically have an onset at childhood. Including these disorders in the utilized hierarchical model would have been complicated. However, exclusion of internalizing comorbidities is not expected to affect the conclusions drawn from our results.

\section{Conclusions}

The study supports previous findings of association between smoking during pregnancy and offspring ADHD. In future studies utilization of biological markers of smoking such as cotinine levels would confirm the present results. The children with the combination of ADHD and CD/ODD show more tendency to develop mood disorders [43] and later criminal activity [44] compared to children with ADHD only. The strong association between prenatal smoking exposure and comorbid CD/ODD and ADHD warrants further research considering the higher risk among these subjects of an overall poor health outcome compared to only ADHD. Future studies on ADHD and CD/ODD should examine the association between smoking and these disorders as both independent and comorbid conditions. Our findings add to the mounting evidence that smoking during pregnancy has an adverse effect on the developing fetal brain and is associated with the development of neurodevelopmental disorders. Finally, regardless of the precise pathogenic mechanisms, prenatal smoking represents an important risk factor for the ADHD comorbid with $\mathrm{CD}$.

\section{Additional file}

Additional file 1: Table S1. Overlap between the comorbid diagnostic categories. (DOCX $14 \mathrm{~kb}$ )

\section{Acknowledgements \\ None.}

\section{Funding}

Dr Joelsson received research funding from the University of Turku Graduate School (UTUGS) and Finnish Cultural Foundation. Dr Chudal received grants from Orion Pharma Foundation, Yrjö Jahnsson Foundation and The Finnish Medical Foundation. Dr. Talati is funded by K01-DA029598 from the National Institute of Drug Abuse The study sponsors did not have any role in study design; interpretation of data or in the writing of the report.

The study was conducted at University of Turku, Finland. 


\section{Availability of data and materials}

The data will not be shared as it is because this would be against the terms of the approval of the data protection authority.

\section{Authors' contributions}

All authors contributed to drafting the manuscript, data analysis and interpretation. Study was designed by PJ, RC, AT, AB and ASo. Data was obtained by PJ, RC, ASu and ASo. All authors read and approved the final manuscript.

\section{Competing interests}

The authors declare that they have no competing interests.

\section{Consent for publication}

Not applicable.

\section{Ethics approval and consent to participate}

The study was authorized by the Ministry of Social Affairs and Health (STM/ 1528/2007) and the National Institute of Health and Welfare (THL) with approval from the ethics committee of the hospital district of Southwest Finland.

\section{Author details}

1Department of Child Psychiatry, University of Turku, Lemminkäisenkatu 3, Lastenpsykiatrian tutkimuskeskus, 20014 Turku, Finland. ${ }^{2}$ Department of Psychiatry, Columbia University College of Physicians and Surgeons, New York, NY, USA. ${ }^{3}$ Division of Epidemiology, New York State Psychiatric Institute, New York, NY, USA. ${ }^{4}$ Department of Epidemiology, Columbia University Mailman School of Public Health, New York, NY, USA. ${ }^{5}$ Department of Child Psychiatry, Turku University Hospital, Turku, Finland.

Received: 23 May 2016 Accepted: 18 August 2016

Published online: 31 August 2016

\section{References}

1. Polanczyk G, de Lima MS, Horta BL, Biederman J, Rohde LA. The worldwide prevalence of ADHD: a systematic review and metaregression analysis. Am J Psychiatry. 2007;164(6):942-8.

2. World Health Organization. ICD-10 classifications of mental and behavioural disorder: clinical descriptions and diagnostic guidelines. Geneva: World Health Organisation; 1992.

3. American Psychiatric Association. Diagnostic and statistical manual of mental diseases (DSM-IV). 4th ed. Washington, DC: American Psychiatric Publishing; 1994.

4. Faber A, Kalverdijk $L$, de Jong-van den Berg LT, Hugtenburg JG, Minderaa RB, Tobi H. Co-morbidity and patterns of care in stimulanttreated children with $\mathrm{ADHD}$ in theNetherlands. Eur Child Adolesc Psychiatry. 2010;19(2):159-66.

5. Goldstein S, Schwebach AJ. The comorbidity of Pervasive Developmental Disorder and Attention Deficit Hyperactivity Disorder: results of a retrospective chart review. J Autism Dev Disord. 2004;34(3):329-39.

6. Jensen $\mathrm{CM}$, Steinhausen HC. Comorbid mental disorders in children and adolescents with attention-deficit/hyperactivity disorder in a large nationwide study. Atten Defic Hyperact Disord. 2014;7(1):27-38.

7. Larson K, Russ SA, Kahn RS, Halfon N. Patterns of comorbidity, functioning, and service use for US children with ADHD, 2007. Pediatrics. 2011;127(3):462-70.

8. Thapar A, Cooper M, Eyre O, Langley K. Practitioner Review: what have we learnt about the causes of ADHD? J Child Psychol Psychiatry. 2012;54:3-16.

9. Obel $C$, Linnet $K M$, Henriksen $T B$, Rodriguez $A$, Järvelin MR, Kotimaa $A$, Moilanen I, Ebeling H, Bilenberg N, Taanila A, Ye G, Olsen J. Smoking during pregnancy and hyperactivity-inattention in the offspring-comparing results from three Nordic cohorts. Int J Epidemiol. 2009:38(3):698-705.

10. Langley K, Rice F, van den Bree MB, Thapar A. Maternal smoking during pregnancy as an environmental risk factor for attention deficit hyperactivity disorder behaviour. A review. Minerva Pediatr. 2005;57(6):359-71.

11. Skoglund C, Chen Q, D Onofrio BM, Lichtenstein P, Larsson H. Familial confounding of the association between maternal smoking during pregnancy and ADHD in offspring. J Child Psychol Psychiatry. 2014;55(1):61-8
12. Obel C, Olsen J, Henriksen TB, Rodriguez A, Järvelin MR, Moilanen I, Parne E, Linnet KM, Taanila A, Ebeling H, Heiervang E, Gissler M. Is maternal smoking during pregnancy a risk factor for hyperkinetic disorder?-Findings from a sibling design. Int J Epidemiol. 2011:40(2):338-45.

13. Smith AM, Dwoskin LP, Pauly JR. Early exposure to nicotine during critical periods of brain development: Mechanisms and consequences. J Pediatr Biochem. 2010;1(2):125.

14. Ion R, Bernal AL. Smoking and preterm birth. Reprod Sci. 2015;22(8):918-26.

15. Miguel PM, Schuch CP, Rojas JJ, Carletti JV, Deckmann I, Martinato LH, et al. Neonatal hypoxia-ischemia induces attention-deficit hyperactivity disorderlike behavior in rats. Behav Neurosci. 2015;129(3):309-20.

16. Tran PL, Lehti V, Lampi KM, Helenius H, Suominen A, Gissler M, Brown AS, Sourander A. Smoking during pregnancy and risk of autism spectrum disorder in a Finnish National Birth Cohort. Paediatr Perinat Epidemiol. 2013;27(3):266-74.

17. Gaysina D, Fergusson DM, Leve LD, Horwood J, Reiss D, Shaw DS, Elam KK, Natsuaki MN, Neiderhiser JM, Harold GT. Maternal smoking during pregnancy and offspring conduct problems: evidence from 3 independent genetically sensitive research designs. JAMA Psychiatry. 2013;70(9):956-63.

18. Menezes AM, Murray J, László M, Wehrmeister FC, Hallal PC, Gonçalves H, Assunção MC, Menezes CB, Barros FC. Happiness and depression in adolescence after maternal smoking during pregnancy: birth cohort study. PLoS One. 2013;8(11):e80370.

19. Radigan M, Lannon P, Roohan P, Gesten F. Medication Patterns for AttentionDeficit/Hyperactivity Disorder and Comorbid Psychiatric Conditions in a LowIncome Population. J. child Adolesc. Psychopharmacol. 2005;15(1):44-56

20. Fredriksen M, Dahl AA, Martinsen EW, Klungsoyr O, Faraone SV, Peleikis DE. Childhood and persistent ADHD symptoms associated with educational failure and long-term occupational disability in adult ADHD. Atten Defic Hyperact Disord. 2014;6(2):87-99.

21. Silva D, Houghton S, Hagemann E, Bower C. Comorbidities of Attention Deficit Hyperactivity Disorder: Pregnancy Risk Factors and Parent Mental Health. Community Ment Health J. 2014;51(6):738-45.

22. Ellis LC, Berg-Nielsen TS, Lydersen S, Wichstrøm L. Smoking during pregnancy and psychiatric disorders in preschoolers. Eur Child Adolesc Psychiatry. 2012;21(11):635-44.

23. Talati A, Wickramaratne PJ, Keyes KM, Hasin DS, Levin FR, Weissman MM. Smoking and psychopathology increasingly associated in recent birth cohorts. Drug Alcohol Depend. 2013;133(2):724-32.

24. Tuvblad C, Zheng M, Raine A, Baker LA. A common genetic factor explains the covariation among ADHD ODD and CD symptoms in 9-10 year old boys and girls. J Abnorm Child Psychol. 2009;37(2):153-67.

25. Joelsson P, Chudal R, Gyllenberg D, Kesti AK, Hinkka-Yli-Salomäki S, Virtanen JP, Huttunen J, Ristkari T, Parkkola K, Gissler M, Sourander A. Demographic characteristics and psychiatric comorbidity of children and adolescents diagnosed with ADHD in specialized healthcare. Child Psychiatry Hum Dev. 2016;47(4):574-82

26. Statistical analyses were performed with SAS statistical software SAS Version 9.4; SAS Institute Inc., Cary, NC.

27. Pastrakuljic A, Schwartz R, Simone C, Derewlany LO, Knie B, Koren G. Transplacental transfer and biotransformation studies of nicotine in the human placental cotyledon perfused in vitro. Life Sci. 1998;63(26):2333-42.

28. Dwyer JB, McQuown SC, Leslie FM. The dynamic effects of nicotine on the developing brain. Pharmacol Ther. 2009;122(2):125-39.

29. Abbott LC, Winzer-Serhan UH. Smoking during pregnancy: lessons learned from epidemiological studies and experimental studies using animal models. Crit Rev Toxicol. 2012;42(4):279-303.

30. Gatzke-Kopp LM, Beauchaine TP. Direct and passive prenatal nicotine exposure and the development of externalizing psychopathology. Child Psychiatry Hum Dev. 2007;38(4):255-69. Epub 2007 May 23.

31. Kahn RS, Khoury J, Nichols WC, Lanphear BP. Role of dopamine transporter genotype and maternal prenatal smoking in childhood hyperactiveimpulsive, inattentive, and oppositional behaviors. J Pediatr. 2003;143(1): 104-10.

32. Wilens TE, Vitulano M, Upadhyaya $H$, Adamson J, Sawtelle $R$, Utzinger $L$, Biederman J. Cigarette smoking associated with attention-deficit hyperactivity disorder. J Pediatr. 2008;153(3):414-9.

33. Tandon M, Si X, Belden A, Spitznagel E, Wakschlag LS, Luby J. Parenting practices in pregnancy smokers compared to non-smokers. J Clin Med Res. 2013;5(2):84-91. 
34. Tung I, Lee SS. Negative parenting behavior and childhood oppositiona defiant disorder: differential moderation by positive and negative peer regard. Aggress Behav. 2014;40(1):79-90.

35. Steinberg EA, Drabick DA. A developmental psychopathology perspective on adhd a nd comorbid conditions: the role of emotion regulation. Child Psychiatry Hum Dev. 2015:46(6):951-66.

36. Thakur GA, Sengupta SM, Grizenko N, Schmitz N, Pagé V, Joober R. Maternal smoking during pregnancy and ADHD: a comprehensive clinical and neurocognitive characterization. Nicotine Tob Res. 2013;15(1):149-57.

37. Larsson $H$, Rydén $E$, Boman $M$, Långström N, Lichtenstein $P$, Landén M. Risk of bipolar disorder and schizophrenia in relatives of people with attentiondeficit hyperactivity disorder. Br J Psychiatry. 2013;203(2):103-6.

38. Ford RP, Tappin DM, Schluter PJ, Wild CJ. Smoking during pregnancy: how reliable are maternal self reports in New Zealand? J Epidemiol Community Health. 1997;51(3):246-51.

39. Walsh RA, Redman S, Adamson L. The accuracy of self-report of smoking status in pregnant women. Addict Behav. 1996;21(5):675-9.

40. Roza SJ, Verhulst FC, Jaddoe WW, Steegers EA, Mackenbach JP, Hofman A, Tiemeier H. Maternal smoking during pregnancy and child behaviour problems: the Generation R Study. Int J Epidemiol. 2009;38(3):680-9.

41. Silberg JL, Parr T, Neale MC, Rutter M, Angold A, Eaves LJ. Maternal smoking during pregnancy and risk to boys' conduct disturbance: an examination of the causal hypothesis. Biol Psychiatry. 2003;53(2):130-5.

42. Gyllenberg D, Gissler M, Malm H, Artama M, Hinkka-Yli-Salomäki S, Brown AS, Sourander A. Specialized service use for psychiatric and neurodevelopmental disorders by age 14 in Finland. Psychiatr Serv. 2014;65(3):367-73.

43. Chen MH, Su TP, Chen YS, Hsu JW, Huang KL, Chang WH, Chen TJ, Bai YM. Higher risk of developing mood disorders among adolescents with comorbidity of attention deficit hyperactivity disorder and disruptive behavior disorder: A nationwide prospective study. J Psychiatr Res. 2013:47(8):1019-23.

44. Mordre M, Groholt B, Kjelsberg E, Sandstad B, Myhre AM. The impact of ADHD and conduct disorder in childhood on adult delinquency: a 30 years follow-up study using official crime records. BMC Psychiatry. 2011;11:57.

\section{Submit your next manuscript to BioMed Central and we will help you at every step:}

- We accept pre-submission inquiries

- Our selector tool helps you to find the most relevant journal

- We provide round the clock customer support

- Convenient online submission

- Thorough peer review

- Inclusion in PubMed and all major indexing services

- Maximum visibility for your research

Submit your manuscript at www.biomedcentral.com/submit

) Biomed Central 